\title{
Harmful Algal Blooms and Coastal Business: Economic Consequences in Florida
}

\author{
SHERRY L. LARKIN \\ CHARLES M. ADAMS \\ Department of Food and Resource Economics \\ University of Florida \\ Gainesville, Florida, USA
}

This research was supported by the Florida Agricultural Experiment Station (FAES), Florida Sea Grant, and a grant from the Florida Harmful Algal Bloom Task Force, Florida Marine Research Institute, Florida Fish and Wildlife Conservation Commission. The authors would also like to thank three anonymous reviewers for helpful comments received during the review process.

Address correspondence to Sherry Larkin, Department of Food and Resource Economics, P.O. Box 110240, University of Florida, Gainesville, FL 32611-0240, USA. E-mail:

SLarkin@ufl.edu 


\section{Harmful Algal Blooms and Coastal Business: Economic Consequences in Florida}

The impacts of harmful algal blooms on beachfront tourism-dependent businesses in the Ft. Walton Beach and Destin areas of Northwest Florida were estimated for the 1995-1999 period using monthly gross taxable sales data. Separate time series models for the restaurant and lodging sectors revealed that harmful algal blooms (HABs) were found to reduce restaurant and lodging revenues in the localized study area by $\$ 2.8$ million and $\$ 3.7$ million per month, respectively, which represents a $29 \%$ to $35 \%$ decline in average monthly revenues for each sector during months of red tide incidence. By comparison, a tropical storm was found to reduce monthly restaurant revenues by $\$ 0.5$ million, and each inch of rainfall reduced revenues an additional \$41,000. Adverse weather was not found to affect the lodging sector. While the estimates are conservative given the resolution of data, the magnitude of effects indicate that tourism-dependent communities suffer significant revenue losses due to HABs, which were higher than previous studies indicated and larger than caused by other exogenous events. This underscores the need for effective resource management.

Keywords business losses, economic, Florida, harmful algae blooms, Karenia brevis, red tide, taxable sales

Running Head Harmful Algal Blooms and Coastal Business 
The coastal waters of Florida host many indigenous species of marine algae whose populations are greatly influenced by water quality (e.g., levels of salinity, dissolved oxygen, nutrients, and minerals). Changing water quality can trigger rapid growth in certain algal populations. These algal "blooms" (commonly referred to as harmful algal blooms or HABs) occur naturally along the southwest coast of Florida, as well as other regions in the Gulf of Mexico. During a highdensity bloom, some species of algae produce toxins that are transmitted within the water column and can become airborne. One particular red-pigmented species of marine algae, the dinoflagellate Karenia brevis, produces a suite of as many as nine toxins (Backer et al. 2003). These toxins can kill marine life and contaminate shellfish beds. Aside from the environmental damage, the toxins from $K$. brevis are unique in that they can pose public health concerns from decomposing marine life on beaches and the possibility of neurotoxic shellfish poisoning (NSP) in humans if contaminated shellfish are ingested (Magana et al. 2003). During periods of highdensity K. brevis blooms near beaches, humans can also experience eye, nose, and respiratory irritation, especially if there are onshore winds with breaking surf (Magana et al. 2003). In combination with the unpleasant smells, these conditions can disrupt local beach use and waterfront business patronage. The blooms of $K$. brevis are sometimes so dense that they impart a reddish color to the water, thereby giving rise to the term "red tide".

Several studies have calculated the economic impacts associated with HAB monitoring and management (e.g., water sampling and beach cleanup), reduced fishing (due to closures and NSP warnings), public health effects (costs of medical visits), and reduced tourism for individual HAB events, particularly for specific sectors of the economy (Hoagland and Scatasta 2006; Adams et al. 2002; Hoagland et al. 2002; Andersen et al. 2000; Evans and Jones 2001; Tomerlin and Adams 1999). The fishing-related losses calculated for events from 1997 to 2005 ranged 
from $\$ 10$ million for closure of a recreational fishery in Washington State to $\$ 50$ million for closure of a recreational and a commercial fishery in Maryland (Hoagland and Scatasta 2006 and Hoagland et al. 2002, respectively). Direct losses to the fishing and tourism sectors, including the cost to cleanup, was estimated at $\$ 10$ million following an event in Texas in 2000. Including subsequent impacts on the statewide economy increased the impacts to $\$ 18$ million (Evans and Jones 2001). HAB induced losses due to impacts on public health within the United States were estimated at \$22 million per year, on average, from 1987-2002 (Hoagland et al. 2002). Overall, a recent report by the National Oceanic and Atmospheric Administration (NOAA) summarized the majority of this recent literature to conclude that the United States suffers annual losses of $\$ 75$ million in economic impacts due to HABs (Weiher and Sen 2006).

Despite the recent and varied attempts to quantify the economic impacts caused by HAB events, examinations of tourism-dependent businesses are limited in general (Hoagland et al. 2002). By only covering the immediate impacts following single events, such estimates can be subject to recall bias from the use of personal interviews or the estimates were not compared to losses from other exogenous environmental events. For a tourism-dependent state that is particularly dependent on marine-based recreational activities such as Florida, this information need is critical.

A recent time-series study in Florida attempted to measure recreational and tourism effects resulting from red tide events near a series of barrier islands in the Sarasota and Manatee Counties region (Adams et al. 2000). Although the study did show a negative impact on beach attendance during a red tide, the analysis did not find any statistically significant economic effects on the local business community resulting from red tides. The resulting inability to isolate a change in business activity due to red tide events may be due to (1) the absence of an effect of 
red tides on local business communities, (2) the data being collected on a spatial and temporal resolution that is too coarse to allow detection of red tide effects (i.e., lost revenues may have been recovered during the same month the red tide event occurred), and or expenditure effects of a red tide event were dissipated because business patrons had alternatives within the study region on which to spend money during a red tide event.

The purpose of this study is to generate information that would provide for a better understanding of the economic consequences to coastal businesses of red tide events in Florida. This is accomplished by considering the results of Tomerlin and Adams (1999) and applying the methodology of Adams et al. (2000) to a localized economy that is less diverse in general and heavily dependent on beachfront business activity, namely the Ft. Walton Beach and Destin areas of Okaloosa County, Florida. The focus on business revenues derived from restaurant and lodging establishments allows for the use of consistently reported gross taxable sales data that is correlated with tax revenues accruing to the local community and reflective of beach and tourism activity. The focus on a smaller geographical region than in the Adams et al. (2000) study (i.e., 10 miles versus 30 miles of beachfront) allows for an estimation of the effects of red tides that have not been mearsured for areas that include larger coastal and inland areas. Using data from 1995 through 1999 allows for the capture of both red tide events and tropical storms (including hurricanes), which are hypothesized to have the same negative impact on business revenues.

Red tides have a long history in Florida, with the earliest recorded event dating to the $1800 \mathrm{~s}$ (Kusek et al. 1999), and red tides are likely to continue, with recreation and tourism expenditures declining (at least in the short run) due to the inhospitable beach environment and potential sickness from red tide toxins. As a result, credible estimates of business losses obtained from a study period that covers multiple environmental events is needed to help guide policy and 
research funding decisions. This information need is especially important given that state funds for red tide events in Florida that are used for research, monitoring, and cleanup are typically from non-recurring sources. Funding levels and allocation decisions are often ad hoc and reactive in nature. To that end, this study will estimate the absolute and relative effect of a red tide event on the restaurant and lodging sectors of a small, localized economy that can potentially be used in benefit transfer analyses. Such information is expected to affect decisions regarding HAB awareness campaigns, research (including monitoring and forecasting), and management such that they may be more efficacious by providing a better understanding of the economic consequences for the local business community.

\section{Data}

Secondary sales data for two business activities representing the restaurant and lodging sectors of Ft. Walton Beach and Destin were obtained from the Florida Department of Revenue (FDOR). Each business in Florida is required to report sales data during the prior month to FDOR, thus these data are only available on a monthly basis. The Retail Sales and Use Tax Business Classifications for these two business sectors are 08 (restaurants) and 39 (hotels and motels). These business sectors were selected because they are the largest and are representative of beach and tourism activities that are likely to be impacted during a red tide event. In addition, since lost daily restaurant revenues cannot be entirely recaptured and since lodging reservations are often accompanied with a deposit and employee requests for time off (i.e., vacation time can be difficult and costly to reschedule), the potential for delayed and or recaptured sales is limited. In an effort to isolate the effect of red tide events on business activities located closest to the water, the data were requested for two zip codes, 32541 (Destin) and 32548 (Ft. Myers Beach, along the barrier island beaches, the waterfront on the "narrows" just north of Okaloosa Island, and the 
western shore of Choctawhatchee Bay south of Gap Creek). These monthly data were obtained for a five-year period beginning January 1995.

The real gross taxable sales revenue in Ft. Walton Beach and Destin were corrected for the general inflation using the CPI such that figures are based on January 1995. The revenues generated by the two business types are characterized by strong seasonal variations that reflect intrayear variation in tourist activity. The peak revenue generating months are generally those in the early to late summer (April through August) (Fig. 1). In terms of monthly revenue (sales), each sector is nearly identical in size over the study period; restaurant and lodging sales averaged \$9.6 million and \$9.4 million, respectively. The lodging sector is, however, more variable. Monthly revenues ranged from $\$ 1.8$ million to $\$ 32.1$ million for the lodging sector during the study period compared to a range of $\$ 4.8$ million to $\$ 21.1$ million for the restaurant sector. Both sectors have shown an increase in revenues during the tourist season from 1995 to 1999 , which likely reflects an increase in the number of reporting establishments and not just an increase in sales for a given number of businesses.

The data on tropical storm conditions, including hurricanes, and precipitation were obtained from the National Climatic Data Center (NCDC). The closest NCDC precipitation reporting station to the Ft. Walton Beach and Destin areas is Pensacola. These data were used as a proxy for rainfall in the Ft. Walton Beach and Destin communities. Only three tropical storms or hurricanes were recorded during the study period, or $5 \%$ of the 60 -month study period (Table 1). Rainfall ranged from zero to approximately 20 inches per month, but averaged 5.8 inches from January 1995 through December 1999 (Fig. 2).

The data on red tide occurrences in the areas of interest were obtained from Red Tide Status Sheets compiled by the Florida Marine Research Institute, Florida Fish and Wildlife 
Conservation Commission. Following the results of Tomerlin and Adams (1999) and subsequent examination by Adams et al. $(2002 ; 2000)$, a binary variable was used to indicate the presence of a red tide event. This variable took the value of 1 for months when a red tide was at least within the low intensity level range (i.e., at least 10,000 cells per liter) on a four-level scale, and 0 otherwise. In the data set used for the current study, four red tide events covering eight (13\%) of the 60-month study period were recorded (Table 1).

\section{Empirical model}

A multiple regression time series model was used to measure the impact of a red tide event on the business activity in the combined Ft. Walton Beach and Destin areas of Florida. The dependent variable measures the level of business activity $(Y)$, which is assumed a linear function of variables that account for both time and environmental conditions:

$$
Y_{i, j, k}=\beta_{o}+\sum_{j=2}^{12} \beta_{j} D_{j}+\gamma T_{j, k}+\sum_{l=1}^{2} \alpha_{l} W_{j, k, l}+\phi P_{j, k}+\varepsilon_{i, j, k}
$$

where $i$ identifies two business types ( $i=$ restaurants, lodging); $j$ and $k$ index months $(j=1,2, \ldots$ $12)$ and years $(k=1995,1996, \ldots 2000)$, respectively; and $l$ indexes two types of environmental events ( $l=1$ for storms, 2 for red tides). The dependent variable $(Y)$ is measured by real gross revenues for each business type in Ft. Walton Beach and Destin. Although the use of real figures will adjust the series for inflation, strong seasonal variations are expected due to monthly variation in tourist activity.

The monthly dummy variables, $M$, identify months February $(j=2)$ through December $(j=$ 12). January $(j=1)$ is used as the base month. The coefficients of the monthly dummy variables will reflect the seasonal nature of business activities in the geographical areas of interest. Since the revenues generated by the two business types are characterized by strong seasonal variations 
as evidenced in Figure 1, the signs of the coefficients for these seasonal dummy variables are expected to vary by each business type. For example, the peak revenue generating months of April through August are expected to have positive signs and larger coefficients than the remaining months. The variables representing months when environmental events such as tropical storms or hurricanes are more likely (i.e., June and August through December in this data set; Table 1) may capture a share of the effects of economic conditions. If so, the monthly and environmental variables will be biased upward and downward, respectively, resulting in conservative estimates of the environmental effects.

Time series data in business and economic applications are typically characterized by a deterministic time trend that cannot be captured with the available data. In this analysis, information on the number of reporting establishments is unavailable but hypothesized to have increased overtime. ${ }^{1}$ This assertion is supported by the recent ranking that the Ft. Walton BeachCrestview-Destin area received based on 5-year estimates of job growth, salary growth, and local GDP (Devol et al. 2006). The Milken Institute rated this area as the Best Performing City in the Smallest Metros category during 2005, which capped a steady rise in the ranking over time for this area. In this study, an increase in the number of businesses over time would be highly correlated with time and with the total taxable gross sales of the tourism-dependent businesses examined in this study. Thus, a general time trend $(T)$ is included that begins with a value of 1 in January 1995. The a priori expected sign for the trend term, $T$, is positive. This reflects the hypothesis that, over the long term, increases in business activities lead to some gradual growth in reported real gross taxable sales in the local economy.

$W_{l}$ represents two binary variables included to capture the presence of any storm that reached at least a tropical storm categorization (including hurricanes) and all red tide events. $W_{l=1}$ equals 
1 for months when a tropical storm or hurricane occurred and $W_{l=2}$ equals 1 for months when a red tide event of at least low intensity occurred, and 0 otherwise for each. $P$ is precipitation measured in inches. The revenues of restaurants and lodging establishments (hotels and motels) are expected to be indirectly related to inclement environmental conditions with respect to human use of the beachfront areas. Since red tides from K. brevis in particular are associated with fish kills, eye irritations, and nasal and other respiratory distresses, the occurrences of red tides in Florida are hypothesized to reduce beach and water-related activity resulting in a negative impact on business revenues (especially after such events have been reported by the local media despite their intensity). The same hypothesis applies to precipitation associated with storms. Consequently, negative signs are expected for all of the environmental coefficients (i.e., $W_{l}$ and $P$ variables).

\section{Estimation procedure and results}

The models were initially estimated separately by ordinary least squares using the Time Series Processor (TSP) computing software. The Durbin-Watson (DW) statistics revealed first order autocorrelation of the error terms. ${ }^{2}$ A maximum likelihood procedure, which imposed stationarity on the data and utilized a grid search for the serial correlation parameter, was used to transform the data and thereby correct for autocorrelation. The models were then estimated with the generalized least squares (GLS) estimator.

Table 2 shows the GLS estimation results including model statistics. The DW statistics reveal that autocorrelation was corrected and suggest that time is properly accounted for in the model. The models appear to fit the data well as reflected in relatively high coefficients of determination (i.e., adjusted $\mathrm{R}^{2}$ of $88.5 \%$ and $90.0 \%$ for restaurants and hotels/motels, respectively) and high Fstatistics. The signs of the coefficients for the time trend $(T)$, hurricanes/tropical storms $\left(W_{l=1}\right)$, 
red tide $\left(W_{l=2}\right)$, and precipitation $(P)$ meet a priori expectations. The monthly dummies $(D)$ also show the expected pattern of relative importance for seasonal tourism.

The coefficients for the monthly dummy variables were statistically significant and positive in March through September in both the restaurant and lodging models. For the restaurant sector, with average sales of $\$ 5.9$ million in January (the base month), the estimated increase in sales ranged from $\$ 3.0$ million in March to nearly $\$ 8.9$ million in July, which represents increases of $52 \%$ and $153 \%$, respectively. For the lodging sector, with lower average sales of $\$ 3.7$ million in January (the base month), the estimated increase in sales ranged from $\$ 3.0$ million in March (the same as the restaurant sector) to nearly $\$ 19.9$ million in July, which represents increases of $82 \%$ and $537 \%$, respectively. Clearly, the lodging sector exhibits greater seasonal variability in taxable revenues.

The coefficient for the time trend variable was also statistically significant in both models and nearly identical for each sector. The trend variable coefficient indicates that sales increased $\$ 119,000$ and $\$ 116,000$ on a monthly basis for restaurants and lodging establishments, respectively. Given average monthly sales of $\$ 9.6$ million and $\$ 9.4$ million for restaurants and lodging establishments, respectively, the monthly trend in sales (perhaps reflecting an increase in the size of the sector in terms of number of establishments) increased just $1.2 \%$.

The presence of a hurricane or tropical storm was found to reduce restaurant sales by $\$ 532,000$ for every month affected. Given that average monthly restaurant sales in August and September were $\$ 12.9$ million and $\$ 9.4$ million, respectively, tropical storms reduced restaurant revenues during the study period by $4.1 \%$ to $5.7 \%$. This relatively small effect could reflect the short duration of such events (i.e., storms rarely last more than a few days) compared to the temporal resolution of the data that allows for such effects to be recovered. The negative 
coefficient for the lodging sector, while larger, was not statistically significant, suggesting that the lodging sector was unaffected by tropical storms or hurricanes. This result could indicate that lodging reservations often cannot be canceled without penalties near the reservation date.

The presence of a red tide event resulted in a statistically significant decline in taxable sales for both restaurants and lodging establishments during the 1995 through 1999 period in the Fort Walton Beach and Destin areas of Florida. Specifically, the presence of a low intensity red tide event or stronger reduced monthly restaurant and lodging revenues by approximately $\$ 2.8$ million and \$3.7 million, respectively. When comparing these effects with the average monthly sales across months during which the red tide events occurred, which were $\$ 9.4$ million for restaurants and \$10.7 million for lodging establishments, red tide events reduced average monthly revenues by $29.3 \%$ and $34.6 \%$, respectively. In total, the tourism-dependent sectors included in this study "lost" approximately $\$ 6.5$ million (32.3\%) in each month that a red tide event of at least low intensity occurred.

The precipitation coefficient indicated that every one inch of rain reduced restaurant sales by an additional $\$ 41,000$ per month, but did not affect lodging revenues (while the coefficient was much larger at $\$ 505,000$, it was not statistically significant). For comparison, average rainfall is 5.8 inches, which translates to a reduction in sales of $\$ 237,800$, which is $2.5 \%$ of monthly average sales for the restaurant sector.

In summary, while the lodging sector is more variable on an annual basis, it was not affected by either tropical storm or precipitation levels but did suffer larger relative losses in sales due to red tide events. Thus, the exogenous environmental events modeled in this study had disproportionate effects on different sectors of the tourism-based business community in the Ft. Walton Beach and Destin areas of Florida during the late 1990s. In addition, the relatively large 
effects associated with red tide events resulted from conservative modeling assumptions, including the identification of red tide events down to 10,000 cells per liter, which captures low, medium, and high intensity red tide levels.

\section{Summary}

Prior to this study, estimates of business losses due to HAB events have been derived from case studies involving post-event interviews and other anecdotal information. This study employed a more rigorous empirical methodology for estimating impacts from multiple HAB events and from other exogenous environmental events (i.e., tropical storms), the latter of which were hypothesized to similarly impact sales. This approach uses a time series of reported taxable income from business sectors that are located near the waterfront and are dependent on beachfront conditions (i.e., restaurants and lodging). Results indicated statistically significant declines in business activity associated with the presence of red tide of at least low intensity; average monthly revenue was estimated to fall 32.3\% ( $\$ 6.5$ million) for the combined restaurant and lodging sectors for months with reported red tide events (and fall $68.4 \%$ compared to the average annual revenue). For a three-month red tide, the total direct impacts would be a loss of $\$ 19.5$ million to the restaurant and lodging sectors, which exceeds previous estimates of single events that include additional sectors as reported by Weiher and Sen (2006). Hence, the most recent national estimates of losses due to red tides may be significantly underestimated.

Coastal counties in Florida have municipal and or county staff that are tasked with decisionmaking (such as allocation of disaster relief funding) regarding waterfront planning, beach use, storm preparedness and other activities that relate to the coastal environment. For some counties, a history of red tides has necessitated the development of protocols that apply during a red tide event. These protocols provide guidance to local officials regarding red tide monitoring, public 
awareness, health advisories, beach cleanup and media contact. Each of these items requires the use of scarce municipal and county funding. Making certain these funds are used efficaciously with respect to red tide events is important, particularly in regions where red tide events occur on a much more frequent basis. Such decisions associated with beach clean-up, educational activities, and other HAB-related expenditures can be better made with a more complete understanding of the magnitude of revenue losses resulting from red tides. Moreover, costly efforts at improving monitoring and prediction of red tide events might be better justified with this information, especially the finding that red tide can reduce local revenues by 29.3 and $34.6 \%$ for the restaurant and lodging sectors, while the passage of a tropical storm (or hurricane) could only result in the loss of $4.8 \%$ for the restaurant sector only.

While this study was able to contribute to the growing literature on the economic impacts of environmental events by using a time-series analysis of reported business revenues, including multiple business sectors and capturing red tide and tropical storm events, certain limitations remain. Since revenues are only available on a monthly basis, factors such as red tide intensity and duration and wind speed and direction that can exacerbate or ameliorate the effects on a daily basis cannot be captured. Thus, proprietary data from establishments are needed to more precisely measure the short and long run impacts of a red tide event. Inclusion of individual firmlevel information associated with each type of event, such as cancellations, sales losses, cleanup costs, and red-tide related promotion, would improve the precision of red tide impact estimates.

\section{Notes}

1. At the time of the study, the FDOR would only provide data for which there were at least 10 reporting establishments within each zip code and for each business code. These constraints did 
not preclude the use of any data for this analysis, but only ensures that there were at least 20 reporting establishments in each month for each business type (10 from each zip code).

2. Separate estimations were maintained (versus interaction terms with each variable to distinguish between business types) in order to improve the efficiency of the correction for autocorrelation and to facilitate the analysis of results. Since the independent variables are identical for both sectors, a seemingly unrelated regression procedure would not improve the results. Preliminary analyses also estimated separate models for each area, however, F-tests revealed that the coefficient estimates were not statistically different between areas (Adams et al. 2002). The analysis reported in this paper uses the combined data.

\section{References}

Adams, C. M., D. Mulkey, S. Holland, A. Hodges, and J. W. Milon. 2000. Development of an economic impact assessment methodology for occurrence of red tide. Gainesville, FL: Staff Paper SP 00-12, Food and Resource Economics Department, University of Florida.

Adams, C., S. Larkin, D. Mulkey, A. Hodges, Ballyram. 2002. Measuring the economic consequences and public awareness of red tide events in Florida. St. Petersburg, FL: Harmful Algal Task Force, Florida Marine Research Institute.

Anderson, D. M., P. Hoagland, Y. Kaoru, and A. W. White. 2000. Estimated annual economic impacts from harmful algal blooms (HABs) in the United States. Woods Hole, MA:

Technical Report WHO-2000-11 Woods Hole Oceanographic Institution.

Backer, L. C., L. E. Fleming, A. Rowan, Y.-S. Cheng, J. Benson, R. H. Pierce, J. Zaias, J. Bean, G. D. Bossart, D. Johnson, R. Quimbo, and D. G. Baden. 2003. Recreational exposure to aerosolized brevetoxins during Florida red tide events. Harmful Algae 2:19-28. 
Devol, R., L. Wallace, and A. Bedroussian. 2006. Best Performing Cities 2005: Where America's Jobs are Created and Sustained. Santa Monica, CA: The Milken Institute.

Evans, G. and L. Jones. 2001. Economic impact of the 2000 red tide on Galveston County, Texas: A case study. College Station, TX: Department of Agricultural Economics, Texas A\&M University.

Hoagland, P., D. M. Anderson, Y. Kaoru, and A. W. White. 2002. The economic effects of harmful algal blooms in the United States: Estimates, assessment issues, and information needs. Estuaries 25(4b):819-837.

Hoagland, P. and S. Scatasta. 2006. The economic effects of harmful algal blooms. In Ecology of Harmful Algae, eds. E. Graneli and J. Turner, chp 29. Dordrecht, The Netherlands: SpringerVerlag.

Kusek, K. M., G. Vargo, K. Steidinger. 1999. Gymnodinium breve in the field, in the lab, and in the newspaper - a scientific and journalistic analysis of Florida red tides. Contributions in Marine Science 34:1-229.

Magana, H. A., C. Contreras, T. A. Villareal. 2003. A historical assessment of Karenia brevis in the western Gulf of Mexico. Harmful Algae 2:163-171.

Tomerlin, A. T., and C. M. Adams. 1999. The economics of harmful algal blooms (HABs): An annotated bibliography. Gainesville, FL: Technical Paper TP-98, Florida Sea Grant College Program.

Weiher, R. and A. Sen. 2006. Economic statistics for NOAA, $5^{\text {th }}$ ed. Silver Spring, MD: U.S. Department of Commerce. 
Table 1. Incidence of environmental events in Ft. Walton Beach and Destin, Florida, 1995-1999

\begin{tabular}{lcc}
\hline & $\begin{array}{c}\text { Hurricane or Tropical Storm } \\
\left(W_{l=l}=1\right)\end{array}$ & $\begin{array}{c}\text { Red Tide } \\
\left(W_{l=2}=1\right)\end{array}$ \\
\hline Event 1 & August 1995 & June 1996 \\
Event 2 & September 1995 & October 1996 \\
Event 3 & September 1998 & September 1998 \\
Event 4 & None & August - December 1999 \\
\hline
\end{tabular}

Note: During these months, the corresponding variable $\left(W_{l}\right.$ or $\left.W_{2}\right)$ will have a value equal to one. In all other months the values of these variables is zero. 
Table 2. Regression coefficients for restaurant and lodging (hotels and motel) revenue models

\begin{tabular}{|c|c|c|c|c|}
\hline & \multicolumn{2}{|c|}{ Restaurants } & \multicolumn{2}{|c|}{ Hotels \& Motels } \\
\hline & Coefficients & $\begin{array}{l}\text { Standard } \\
\text { Errors }\end{array}$ & Coefficients & $\begin{array}{c}\text { Standard } \\
\text { Errors }\end{array}$ \\
\hline \multicolumn{5}{|l|}{ Variable } \\
\hline Constant & $2.920^{*}$ & 1.277 & 1.171 & 1.337 \\
\hline February $\left(D_{2}\right)$ & 0.477 & 0.293 & 0.853 & 0.691 \\
\hline $\operatorname{March}\left(D_{3}\right)$ & $3.018^{*}$ & 0.391 & $3.043 *$ & 0.887 \\
\hline April $\left(D_{4}\right)$ & $3.711 *$ & 0.454 & $5.074 *$ & 1.003 \\
\hline May $\left(D_{5}\right)$ & $4.805^{*}$ & 0.495 & $6.939 *$ & 1.072 \\
\hline June $\left(D_{6}\right)$ & $7.134 *$ & 0.524 & $14.519^{*}$ & 1.122 \\
\hline July $\left(D_{7}\right)$ & $8.878^{*}$ & 0.535 & $19.863^{*}$ & 1.139 \\
\hline August $\left(D_{8}\right)$ & $6.826^{*}$ & 0.528 & $11.574^{*}$ & 1.127 \\
\hline September $\left(D_{9}\right)$ & $3.372 *$ & 0.505 & $4.633^{*}$ & 1.089 \\
\hline October $\left(D_{10}\right)$ & $1.509 *$ & 0.473 & 1.587 & 1.043 \\
\hline November $\left(D_{11}\right)$ & 0.0793 & 0.411 & -0.826 & 0.927 \\
\hline December $\left(D_{12}\right)$ & 0.312 & 0.334 & -0.828 & 0.777 \\
\hline Time Trend $(T)$ & $0.119 *$ & 0.034 & $0.116^{*}$ & 0.035 \\
\hline Storm $\left(W_{l}\right)$ & $-0.532 *$ & 0.262 & -0.991 & 0.631 \\
\hline Red Tide $\left(W_{2}\right)$ & $-2.751^{*}$ & 0.739 & $-3.703 *$ & 1.476 \\
\hline Precipitation $(P)$ & $-0.041^{*}$ & 0.021 & -0.505 & 0.496 \\
\hline \multicolumn{5}{|l|}{ Equation Statistics } \\
\hline Observations & 60 & & 60 & \\
\hline Adjusted $\mathrm{R}^{2}$ & 0.885 & & 0.900 & \\
\hline DW-Statistic & 1.759 & & 1.811 & \\
\hline F-Statistic & 31.035 & & 36.374 & \\
\hline Rho & $0.900^{*}$ & 14.158 & $0.700^{*}$ & 6.777 \\
\hline
\end{tabular}

Note: Asterisk indicates coefficient is significant at $p<0.5$. 


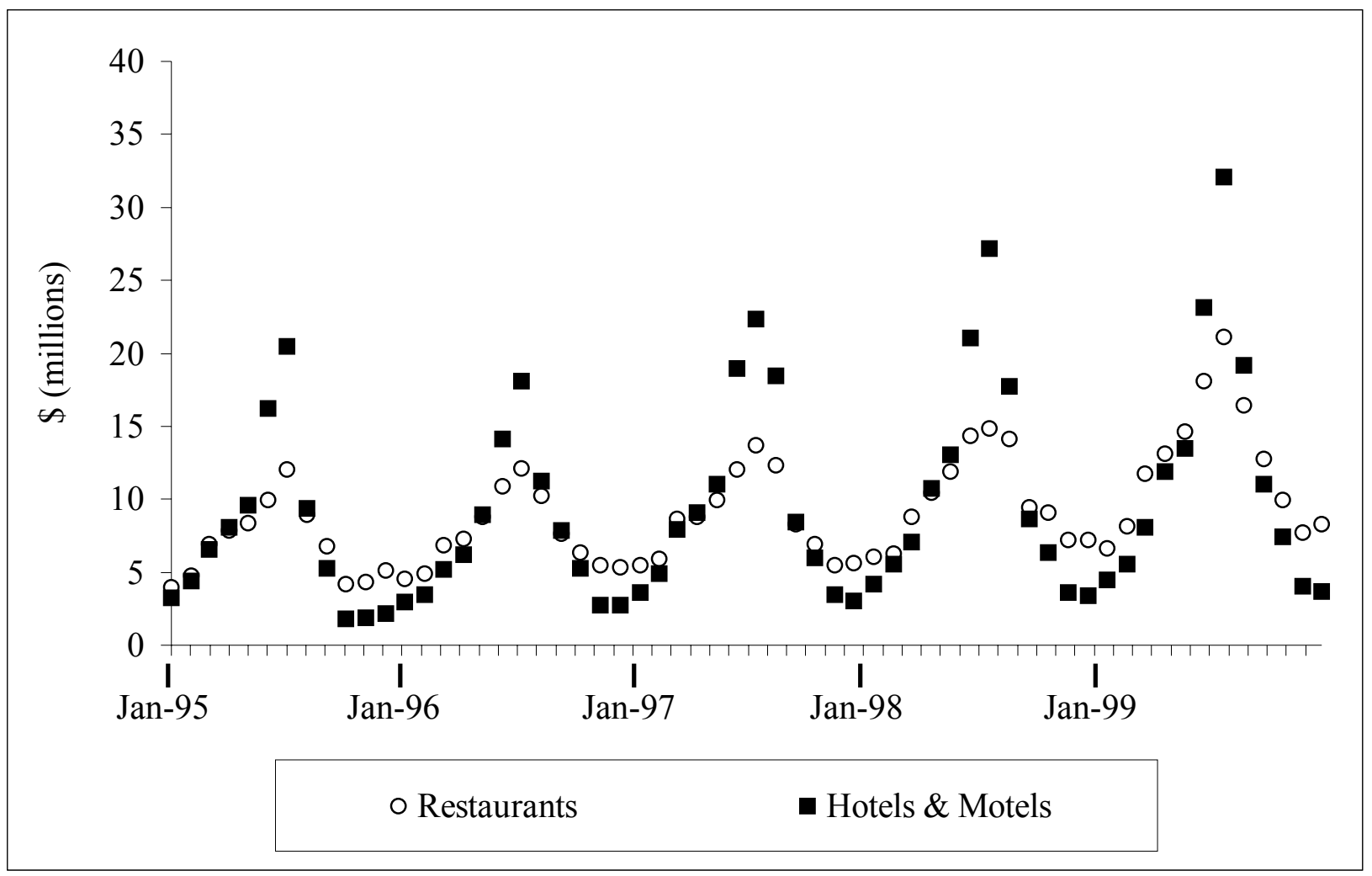

Figure 1. Real monthly gross taxable sales revenues for hotels/motels and restaurants in the Ft. Walton Beach and Destin areas, Florida, 1995-1999. 


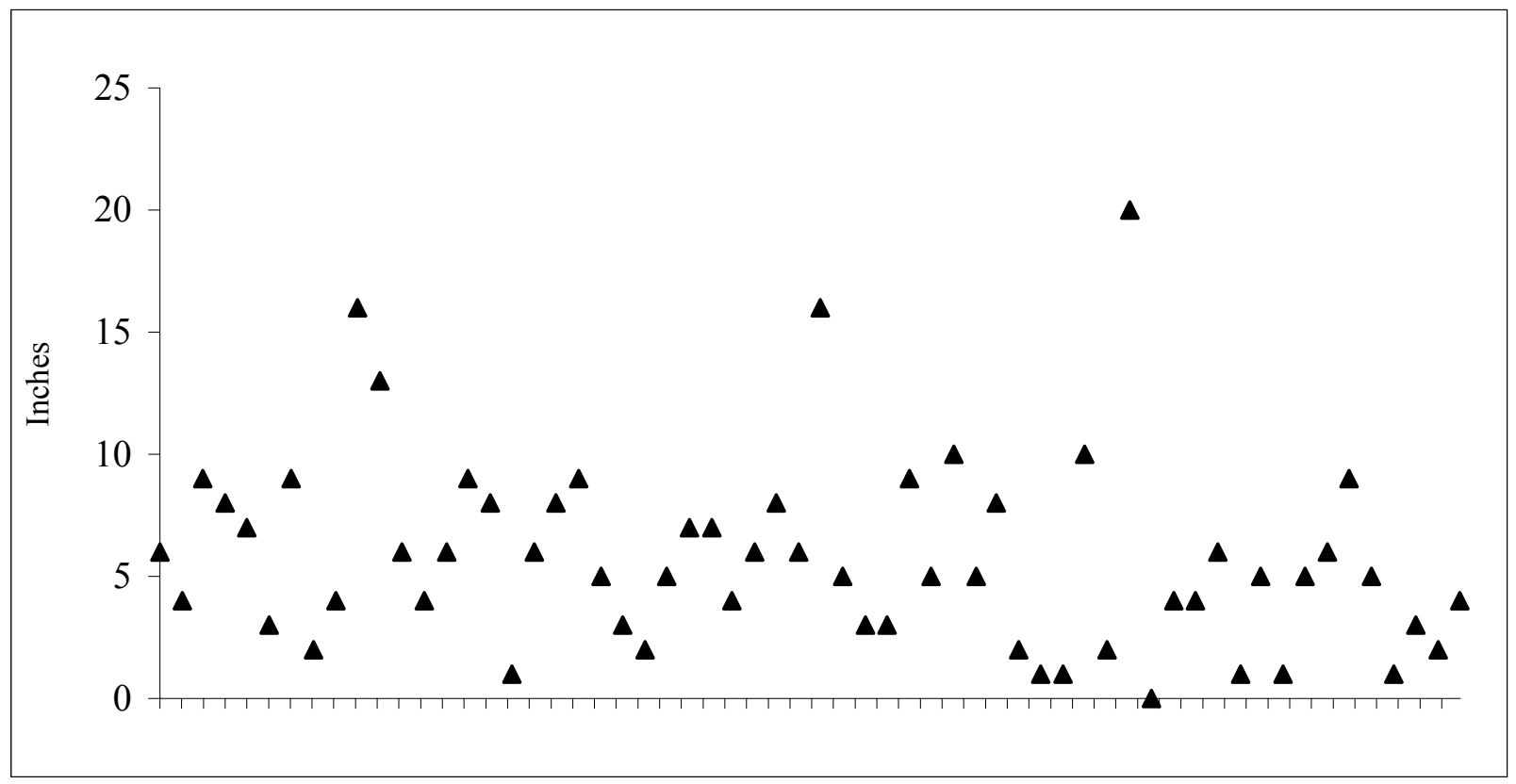

Figure 2. Monthly precipitation in the Ft. Walton Beach and Destin areas, Florida, 1995-1999. 